\title{
Trazendo para debate a preocupação com a formação dos professores para o ensino básico
}

\footnotetext{
Alberto Nicodemo Senapeschi
}

Palavras-chave: ciência; tecnologia: formação de professores; ensino básico.

\section{Resumo}

Debate a preocupação com a formação dos professores para o ensino básico, considerando as características da sociedade tecnológica e as necessi dades educacionais da população com vistas a sua inserção social plena. Para apresentar e desenvolver as idéias, são trazidas opini ões de pessoas pertencentes a diferentes setores da sociedade. Al gumas questões são col ocadas para refl exão, visando estimular o debate sobre o tema.
A sociedade que mal trata seus professores básicos ainda vive da ignorância popular. Com efeito, o sistema não teme um pobre com fome. Teme um pobre que sabe pensar. O "barateamento" da formação do professor inicial, em vez defacilitar o acesso ao saber pensar, faz parte da estratégia clássica de imbecilização. Engraçado, só se aceita encurtar a formação do professor inicial

(Demo, 2000, p. 9).

\section{Introdução}

Entre 18 e 21 de setembro de 2001, foi realizada, em Brasília-DF, a Conferência Nacional deCiência, Tecnologiaelnovação, encontro em que se avaliou a situação da Ciência, Tecnol ogia e Inovação (CT\&l) no Brasil, eem que foram propostas estratégias para o desenvolvimento científico e tecnológico do País, inclusive com a maior partici pação dos empresários do setor. Um dos grandes resultados da Conferência foi o de consol idar, entreacadêmicos eempresários, a idéia de que a empresa éo local da inovação ea universi dadeéo lugar da educação eda ciência.
Francisco Romeu Landi - na oportunidade diretor-presidente da Fundação de Amparo à Pesquisa do Estado de São Paulo (Fapesp) - , referindo-seà conferência, não sem antes se descul par pela simplicidade do model o queutilizou para destacar aquilo que mais o sensibilizou após participar dela, ressal tou:

Dizia Clausewits que uma guerra se ganha com um exército bem treinado; modernas armas; uma firme logística de suprimentos contínuos para a frente de batal ha; um Estado-Maior organizado, que saiba definir as necessidades e as prioridades das batalhas; e um bom sistema de comunicações. Na luta para implantar de fato a cultura de que CT\&l são os el ementos estratégicos dos planos de desenvolvimento das nações, temos nós um espaço para a sociedade brasileira? Parece-me que sim. Temos um "exército" precário na base, mas com bons "oficiais". O nosso sistema de educação básica, média e superior ainda deixa muito a desejar e temos muitos anos de enorme esforço pel a frente. Curiosamente, porém, a nossa pós-graduação apresenta excel ente qualidade. Formamos cinco mil doutores por ano, índice comparável ao de algumas nações 
desenvolvidas. A nossa produção de papers já coloca o País entre os 20 primeiros (18ㅇ) do mundo. Digamos, pois, que para CT\&l o nosso "exército" em formação tem um bom potencial (Landi, 2001, p. 20).

Quase no mesmo período, Oscar Hipólito - pró-reitor daUniversidade Bandeirantes (Uniban), São Paulo-SP - destacou que, com exceção de alguns poucos centros de excelência, em que ciência e tecnol ogia são desenvolvidas de forma competitiva, o Brasil parece estar perdendo a corrida tecnológica, tanto para os países mais desenvolvidos como para nossos vizinhos da América Latina. Em um dos trechos, o autor diz que:

Um estudo recente, encomendado pela Federação das Indústrias do Estado do Rio de Janeiro (Firjan), mostrou que, se não forem tomadas medidas urgentes para sanar as deficiências, o País corre um sério risco de setornar um excluído tecnológico (Hipólito, 2001, p. 39).

ParaHipólito, o Brasil necessita deuma verdadei ra revol ução na educação, evidenciada pel a situação precária denosso ensino básico e, até de forma mais dramática, segundo ele, do nosso ensino superior de graduação, inclusiveapontando dados elevados de evasão nas instituições deensino superior e de repetências - mais de $40 \%$ dos al unos ingressantes na universidade brasileira não completam o curso no tempo previsto.

Para demonstrar, com mais veemência suas preocupações, o autor aponta que, para cada um milhão de habitantes, temos apenas 180 cientistas, enquanto países como a Argentina têm 700 e os Estados Unidos da América, 3.800. O resultado éque o Brasil amarga um número reduzido de empresas nacionais de base tecnológica, com raras patentes requeridas e um baixo índice de produtos tecnológicos na lista de exportações e conclui:

O desinteresse por ciência, no Brasil, éfruto do declínio da qualidade do ensino básico, de um modo geral e, em especial, do ensino de ciências. O mais grave, entre tanto, équea fal ta de motivação de nossas crianças por ciência em sua quase total idade decorrente do baixo nível dequalificação dos professores licenciados para ciências, acaba comprometendo irremediavel menteo desenvol vimento científico e tecnológico, pondo em risco o futuro do País. Afinal, sabemos que é na escola básica que se desenvol ve o gosto, ou a aversão, pela ciência. Sequisermos ter uma pequena chance de participação nos avanços tecnológi cos e, conseqüentemente, na economia gl obal izada, temos que investir maciça e continuamente em educação, ciência e tecnologia (Hipólito, 2001, p. 39).

Fica evidenciado, na opinião dos dois autores, que o nosso ensino - fundamental, médio e superior - apresenta sérios proble mas. Parecenão haver dúvidas dequea base do "exército"éum sério problema para o futuro tecnológico denosso País. Também, aquestão levantada do baixo nível de qual ificação dos professores licenciados para Ciências podeser estendida para outras licenciaturas. Na verdade, o problema ébem mais sério.

A falta de preparo adequado da base do "exército", conforme aponta Landi, e o despreparo do licenciado para dar as aulas de Ciências no ensino básico, segundo Hipólito, encontram um denominador comum na preocupação com a formação dos professores para o ensino básico, tema central desteartigo.

Assim, procurar-se-á no texto dar especial ênfaseà preocupação com a formação do professor para atuar no ensino básico, a partir das constatações apresentadas deque, aparentemente, nossas crianças não estariam sendo bem preparadas, o que, inclusive, poderia comprometer o futuro científico etecnológico do Brasil, chegando mesmo a torná-lo umexcluído no mundo tecnológico.

O presentetexto tem por objetivo, a partir da problemática acima colocada, proceder a uma revisão da literatura sobre o assunto por intermédio de uma pesquisa bi bliográfi$\mathrm{ca}$, propondo al guns questionamentos para a reflexão do leitor.

\section{Desenvolvimento do trabalho}

O questionário socioeconômico do ExameNacional deCursos de 2001 do MEC mostrou que os formandos decursos como Pedagogia, Letras, Matemática, Biol ogia, Física e Química (os mais procurados pelos que pretendem ser professores) - futuros licenciados - têm perfil muito diferentedaquel esquesaem de cursos mais concorridos (Medicina, por exemplo) ou de oferta mais comumnas faculdades (como Direito eAdmi nistração). 
O professor formado pelas universidades brasileiras, em números preocupantes, éfil ho de pais quenunca foram à escola ou sequer completaram os quatro primeiros anos do ensino fundamental. Eles vivem emfamílias de baixa renda eestudaram em escolas públicas. Muitos no ensino noturno etrabal hando o dia todo.

A Diretoria de Estatísticas e Avaliação da Educação Superior do Instituto Nacional de Estudos e Pesquisas Educacionais Anísio Teixeira (Inep), do Ministério da Educação, pela Revista do Provão 2002, ao apresentar quem são os mais novos profissionais queas nossas facul dades estão preparando para o mercado de trabal ho, constatou queem cursos deformação de professores é maior a presença de al unos de faixas de renda mais baixas, que cursaram o ensino médio em escolas públicas efilhos de pais com baixa escolaridade. Com relação ao grau de escolaridade dos pais, nos cursos de Pedagogia foi registrado o mai or número de formandos cujos pais têm, no máximo, o ensino fundamental completo: $77 \%$. Índices semel hantes foram encontrados nos cursos de Matemática e Letras. ${ }^{1}$

Com este perfil levantado pel o Inep ea inexistência de políticas públicas que garantam uma escol a de qual idade para a classe trabal hadora, éque os al unos chegam às facul dades responsáveis pel a formação de professores.

Há al gumas décadas, o perfil do licenciado era outro; está ocorrendo uma mudança gradativa, cada vez mais acentuada. A defasagem salarial da categoria podeser um dos fatores importantes para quea carrei ra de professor esteja deixando de atrair um público melhor preparado. Hoje, o professor precisa trabal har em vários lugares para garantir sua renda, o que acaba por prejudicar sensivel mente sua formação continuada. A velocidade do progresso científico etecnol ógico eda transformação dos processos de produção tornam o conhecimento rapi damentesuperado, exigindo-se uma atual ização contínua e col ocando novas exigências para a formação do profissional.

Outra vertentea ser consideradaéa de que as instituições de ensino superior públicas não formam muitos professores. Quase sempre, num curso de Física ou de Química de uma universidade pública apenas como exemplos - , a preocupação principal é formar físicos ou químicos, e não professores para o ensino básico.
Como resul tado imediato, por exemplo, na rede de ensino estadual de São Paulo, segundo dados atuais forneci dos pela própria Secretaria da Educação do Estado, 90\% dos professores fizeram facul dades particulares. Muitos fizeram cursos noturnos em instituições em que o ensino é apenas reprodutivista, com professores que se contentam apenas em repassar idéias tais quais eles as receberam de seus autores, sem reflexão, sem produção deconhecimento. Ainda, parcela si gnificativa del es trabal hava o dia todo, durante o curso, sem tempo para um mel hor preparo.

Carlos Heitor Cony, em um de seus ensai os, bem traduz o que está ocorrendo:

Como acontece com quase todos os colegas de ofício, vol ta e meia me pedem para examinar trabal hos escolares que se habilitam a prêmios disso ou daquilo. Semana dessas, integrei comissão que julgou um concurso em nível desegundo grau sobre os 50 anos delsrael. Li os quase cem trabal hos com interessee paciência... Não sou professor. Mas como jornal ista conheço esse sistema de trabal ho, muito usado em redações para dar aos leitores um apanhado geral sobre determi nado assunto ou tema. No caso de um trabal ho escolar, discordo do processo de colagem e pesquisa. Evidente que o aluno tem a obrigação de procurar boas fontes, sejam enciclopédias, entrevistas pessoais, livros, edições especiais, folhetos de propaganda, etc. mas não detranscrevêlas mecanicamente. Antigamente, era na base da tesoura e da cola. Agora, com as gerações informatizadas, o estudante deixa de ser aluno esetorna produtor ou editor. Acredito que se deva incentivar a reflexão do estudante, estimulando-o a pensar e a tirar concl usões sobre o tema indicado. Reflexão que será obtida após a metabolização de todo o material pesquisado, daquilo que o al uno ouviu em aulas, do que sacou por aí. Do contrário, o trabal ho resultará numa simples montagem, sobressaindo-se os candidatos que dispõem de melhores micros, impressoras em cor, os que podem escanear fotose gráficos, etc. No caso dos 50 anos de Israel, dei atodos os al unos, indistintamente, a nota cinco. Evidenteque havia trabal hos mais bem apresentados. Nenhum deles, porém, revelando reflexão, e sim melhor equipamento (Cony, 1999, p. A2).

Cony, que é escritor e jornalista, nos mostra uma tristereal idade. A mai oria dos professores do ensino básico não está preparada para pesquisar, refletir e produzir
Revista do Provão, 2002 p. 12 13. 
conhecimento, decorrendo daí a dificuldade de repassar a seus alunos o que ele (Cony) gostaria de ver nos trabalhos apresentados para o concurso.

Pedro Demo ébastanteenfático ao tratar do assunto; quando, referindo-se aos professores do ensino básico diz:

É comum o professor que apenas ensina, em especial o de 1ㅇ e 2 o graus: estuda uma vez na vida, ameal ha certo lote de conhe cimento e, a seguir, transmite aos al unos, dentro da didática reprodutiva e cada dia mais desatualizada (Demo, 1996, p. 12).

O próprio autor, no entanto, reconhece queestaimagemé parteconstitutiva predominante da universidade, já que a grande mai oria dos seus professores, também, só ensina, contando aos seus al unos - futuros professores - o que aprendem de outrem, imitando ereproduzindo.

Há outra questão muito séria equediz respeito à resistência, na educação, a mudanças e sobre a qual o renomado professor eautor Attico Chassot escreveu que:

Se José de Anchi eta, um dos pioneiros em educação no Brasil, entrasse hoje em nossas sal as de aul a muito pouco se surpreenderia, pois nossos métodos e tecnol ogias são praticamente os mesmos por el e utilizados. Continua-se fazendo educação com artesania (Chassot apud Kalinke, 1999, p. 4).

Ainda, há a falta de professores para que a própria LDB seja cumprida. Segundo o sociólogo Simon Schwartzman, o Brasil precisaria formar 147 mil professores a mais por ano para conseguir cumprir a sua própria Lei deDiretrizes e Bases daEducação Nacional.

A preocupação com o ensino fundamental, médio e superior deve estar presenteno meio universitário. Não podeser rel egada. Precisa ser debatida e soluções precisam ser encontradas.

Furlani (1999), em sua tese de doutorado, escreveu um tratado sobre os al unos do ensino superior noturno, pela palavra do próprio aluno, abordando diferentes aspectos deseu itinerário escolar, no movimento dialético endógeno à realidade. $\mathrm{O}$ estudo, que teve como público-al vo estudantes da Bai xada Santista, Estado de São Paulo, ${ }^{1}$ enfocou o ensino noturno em instituições de ensino superior privadas, certamente responsáveis pela formação de grandenúmero deprofessores do ensino fundamental emédio, queestão atuando no Estado de São Paulo, principal mente se considerarmos os dados de que $90 \%$ dos professores da rede estadual são oriundos de faculdades particulares.

Muitas questões levantadas e discutidas no trabal ho nos mostram e confirmam nossas preocupações com a formação do professor para o ensino básico. No entanto, um dado, em particular, nos chamou a atenção. A té mesmo aquel e al uno que vinha se interessando pela carreira de professor, diante do seu perfil - nível soci oeconômico e facul dade particular - , está buscando outros caminhos, o que certamente poderá colaborar ai nda mai s com o declínio da profissão.

Os depoi mentos de três al unos, entre outros, transcritos no trabal ho evidenciam que o desinteresse pela carrei ra de professor está chegando também ao ensino noturno das instituições particulares diante da crescente desval orização desse profissional e da necessidade de sobrevivência, ficando bem definido que, para el es, a escoIha de uma profissão está rel acionada com - lugar que ela ocupa, sua representação na sociedade e com o prestígio que lhe é associado.

- Na época do vestibular, cheguei a passar no curso de Matemática, mas como professor não consegueviver nestePaís, optei por Computação, por ser dentro da mesmaárea, ter mais mercado de trabal ho e opções profissionais (Depoimento de um aluno formado em Ciência da Computação - instituição particular e curso noturno).

- Eu gosto muito de estudar História; não acho que vou dar aula, pelo menos não vejo isso como meta a ser concretizada a médio prazo. Mas sempre me interessei pela história do mundo, quero dizer, eu comecei a devorar os livros do assunto, quando ganhei de uma professora do primário $A$ história do mundo para crianças. Aí, não parei mais. Acho que vou continuar trabaIhando no meu emprego, porque professor deHistória tem poucas aulas, édifícil você ter um salário digno. Mas paramim foi uma realização ter me formado em História e saber que, no futuro, talvez eu possa me dedicar a estudar mais isso (Depoimento de aluna do ensino superior noturno instituição particular).

- Quando você faz faculdade, é porque você quer crescer, se tornar mel hor. Isso tem um lado financei ro, um lado pessoal

\footnotetext{
1 A autora não relaciona as cida des. Noentanto, as principaiscidades da baixada santistasão: Santos, São Vicente, Guarujá CubatãoePraiaGrande.
} 
etem um lado da sociedade, o do respeito que as pessoas vão ter por você, a sua posição em relação a seus filhos, em relação a seus amigos... (Depoimento de outro al uno do ensino superior noturno instituição particular).

Embora esses depoimentos estejam delimitados para os universitários do noturno e sejam concretos e localizados em uma determi nada região deSão Paulo, eles permitem que sejamos remetidos a real idades sociais mais amplas, pois o recortefeito certamente teve, por objetivo, conhecer o al uno que está inserido em um sistema e contexto de educação predominantes no País.

Ao procurar um curso de graduação, os vestibulandos estão dando prioridade paraas carreiras que oferecem mais chances de sucesso financeiro, status e prestígio. A ptidão, história de vida e desejos de realização acabam ficando em segundo plano, ou, si mplesmente, são ignorados.

Os estudantes estão se dei xando seduzir pela possi bilidadedeascensão social via diploma universitário, optando pelos chamados "cursos de mercado", como Direito, Administração, Informática, entreoutros.

Ainda Furlani, ao analisar outros aspectos do problema, observou que as universidades brasileiras são confrontadas com os grandes desafios que o País enfrenta, entre outros, o defazer frente a um mundo internacional cada vez mais sel etivo ecompetitivo, o que exige políticas bem definidas earrojadas em ciência, tecnol ogia eeducação, bem como o de encontrar soluções para nossos graves problemas sociais, de modo a haver eqüi dadesocial, questão que depende de forte vontade política e grandes modificações na estrutura social .

Ela ainda afirma que o professor éum profissional que não pode ser improvisado, que deve ser compromissado com seu ofício, capacitado a desafiar e estimular a inteligênciadeseus al unos, acreditando que el es podem aprender, propondo aulas que sejam convites ao diál ogo e sugerindo outras atividades, em que os al unos possam retomar os temas tratados, reel aborando-os cientificamente.

Porém, emseu próprio trabal ho, em sua investigação sistemática, ela observou que a própria formação científica que deveria começar na educação básica, continuar na superior e se completar na pós-graduação, raramenteé propiciada aos al unos, aumentando a nossa preocupação com a formação dos professores-licenciados, responsáveis pela"base do exército".

Voltando especificamenteàs preocupações trazidas por Hi pólito, quanto ao nosso futuro científico etecnológico, diante da falta de motivação de nossas crianças por ciência, gostaríamos de nos aprofundar um pouco mais no tema, atémesmo pel a nossa formação acadêmica e experiência profissional em todos os níveis de ensino, desde o fundamental atéa pós-graduação, tanto em instituições públicas como privadas.

Temos ressalvas para aceitar que um "exército" precário na base, mas com bons "oficiais", possa manter um bom potencial. Também, entendemos que não será apenas a má qual ificação dos professores licenciados em Ciências que poderá comprometer o nosso desenvolvimento científico e tecnológico.

Primeiro, vamos nos reportar a trabaIhos publicados, como o de Franco (1991), que faz uma breve revisão da discussão sobreas matrizes epistemológicasqueembasam diferentes concepções de ciência, buscando recuperar o debate para o âmbito educacional. Os resultados da pesquisa, realizada com um grupo de vestibulandos paulistas, acerca das representações que construíram sobre ciência e tecnologia, mostraram que as práticas pedagógicas na área não estavam conseguindo viabilizar a aquisição de um conhecimento crítico em ciênciaetecnologia, à luz das condi ções objetivas da existência social.

É necessário rever a concepção deCiênciae Tecnol ogia, epistemologicamente, a partir de um model o quese afaste da abordagem cientificista, linear eque recupereas rel ações entreconhecer e pensar, ressal tando o papel das rupturas, das descontinuidades edastensões da História, conformepropõeFranco.

José do Prado Martins ébem explícito ao afirmar que:

O paradigma científico, em razão de sua linearidade, leva a um aprofundamento na análise, perdendo o poder desíntese, e a uma centrifugação do conhecimento, que tem por conseqüência a formação do especial ista al ienado, individual ista e autoritário, de visão unidisciplinar, ou seja, aborda o todo, porém sempre sob sua ótica. A unidisciplinaridadeéfinalista, buscando obsti nadamente os objetivos formulados, a fim de obter vantagens e sucesso sem levar em conta as conseqüências de ordem ambiental, humana e social (Martins, 2003, p. 62). 


\section{E, prossegue:}

A educação deve ter por pressuposto bási co queos indivíduos eos grupos humanos são diferentes. Desse modo, deverespeitar as diferenças individuais e suas especificidades para construir-se em fator de coesão e não de exclusão. Assim, deve consi derar como ponto de partida a dimensão político-social do educando, ou seja, que esteéum projeto político da sociedade; valorizar os conteúdos experienciais do educando, os conhecimentos do cotidiano e as habilidades de cada um; em termos metodológicos, deve dar ênfase aos conteúdos procedimentais e atitudinais e ao incentivo à construção do conhecimento (Martins, 2003, p. 67).

Ressal te-se, no entanto, quea preocupação com a qual i dade do ensino de Ciências não éapenas no Brasil. Alarmados com o declínio do interesse dos estudantes do ensino médio em ciência, as autoridades em Educação do Japão planejam reformar o ensino do setor, abandonando o projeto de centrar esforços numa educação padronizada para ressaltar os talentos indi viduais. As escolas deverão criar clubes de ciência eatual izar currículos e métodos com o que demelhor sefaz na universidade.

Também, nos Estados Unidos da América, a Associação Americana para o Avanço da Ciência tem um projeto para consolidar, nos próximos sessenta anos, noções básicas de Ciência e Tecnologia, fazendo uma ampla reforma no sistema educacional, definindo em primeiro lugar que conceitos, para quee, principalmente, por que aprender, em cada fai xa etária.

A exemplo de Franco, Meis também procurou entender como as crianças e os universitários viama ciência, desenvolvendo projetos, cujos resultados são bastante significativos:

Queria ver como éque as crianças viama ciência e pedi que desenhassem o cientista. A partir de uma amostra grandefeita no Brasil e nos Estados Unidos, vimos queo desenho não muda desde que a criança tem 6 ou 7 anos até ela entrar na universidade. É sempre o mesmo desenho machista, não tem mulher fazendo ciência... A coisa passa pelo estereótipo do homem sempre solitário, com a cara meio entediada, não há comuni cação. Mais de $30 \%$ desses desenhos mostravam pessoas que vocênão convidaria para tomar chá em sua casa. Umas caras horríveis, loucos, desvairados... Depois, em outros trabal hos, perguntamos a universitários o queera ciência. Escolhemos os que tinham acabado de passar no vestibular de Medicina, porqueéo mais difícil eque requer mais conhecimento da ciência que se ensi na no colégio, e os meninos da Escola de Belas-Artes. Esperava respostas diferentes. Nada! Todos diziam que a ciência éum negócio lógi co enão precisa de criatividade, porque se descobre o que já está aí... É lógica, observação, precisão... nenhuma emoção, nenhumsentimento. Aí perguntei "o que é arte?", e diziam o contrário: éemoção, criatividade, criar coisas novas, universos (Meis, 2001, p. 90).

Esta visão, apontada quando o estudante tem que tomar sua decisão de carreira, também devecolaborar bastante para o desinteresse crescente pela área de Ciência e Tecnologia no Brasil.

Meis também anal isa a questão das aulas deciências serem chatas, geral mentefato atribuído à desmotivação dos professores:

Sem dúvida isso contribui. Mas, tirando isso, o fato é o seguinte: só mostramos o Iado utilitário da ciência, e o outro lado, igualmente importante e fundamental para o menino em formação, fica esquecido. Ora, um menino de 7, 10, 15 anos, excepcional mente pode até estar interessado em Produto Interno Bruto, mas está muito mais interessado no que el e gosta e no que não gosta. E mostrar que a ciência traz algo muito maior, por exemplo, entender o universo, podeser, para eles, um negócio importante (Meis, 2001, p. 91).

É sabido que, ao longo dos últimos anos, um conjunto de programas como o Pró-Ciências, ${ }^{2}$ preocupado com o aperfei çoamento do ensino de Ciências para jovens, tem si do incentivado e busca oferecer condições para que al unos e professores possam participar criticamente de uma sociedade cada vez mais envolvida pela Ciência eTecnologia.

O Pró-Ciências - Programa de Apoio no A perfeiçoamento de Professores do Ensino em Matemática e Ciências, foi criado justamente com o objetivo de investigar e propor metodol ogias de ensino inovadoras, que repensassem a formação dos professores pelo contato com os avanços produzidos pela Ciência e Tecnologia. Embora a aval iação que setem do Programa, por parte de muitos, seja positiva, faltaram, a nosso ver, mais ousadia, projetos realmente inovadores, quelevassem os avanços recentes

\footnotetext{
O Programa Pró-Ciências foi criado pela Capes/MEC e implementado nos Estados pe lasagências estaduais defomentoà pesquisa eSecretarias Esta duais deEducação com o obje tivo de investigar novas metodologias deensino. NoEstado deSão Paulo, aFapesp foi a responsável pelo Programa.
} 
da Ciência eTecnologia aos professores-alunos, para queel es pudessem real mentediscuti-los com seus al unos, mostrar as aplicações e a importância dos mesmos, não se restringindo apenas em criar materiais alternativos eexperimentos simples ou repor conteúdos. O professor-al uno precisa ser mais exigido, mostrar sua competência e recuperar a auto-estima.

A grande maioria dos projetos aprovados preocupou-se apenas em repor conteúdos, ensinar os professores-alunos a improvisar materiais que Ihes permitissem real izar experimentos simples e baratos ou criar textos apostilados.

Poderiam ter ido além; aproveitar a interação com boas universi dades e exigir dos professores-alunos contato com equipamentos modernos, levá-los a estudar, pesquisar, refletir, produzir, escrever relatórios, enfatizar o caráter indispensável do componente pesquisa para o trabal ho docente, seja el e exercido em qual quer nível deensino.

Para Pedro Demo, citado por Menga Ludkena introdução do livro 0 professor e a pesquisa, o professor precisa refletir sobre sua prática de maneira criativa, ultrapassando os limites de sua sala de aula e desua escola, sempre com os pés fincados nel as e projetando seus pensamentos, idéias e pesquisas para o âmbi to da comunidade em que vive (Lüdke, 2001, p. 9-11).

Ainda, é o próprio Pedro Demo que corrobora o nosso entendimento de projetos inovadores:

Na luta pela val orização do profissional deve entrar com ênfase o compromisso com a pesquisa, no quadro da coerência emanci patória que é sempre o núcleo mais digno da educação. O "professor" (com aspas), para tornar-se PROFESSOR (sem aspas e com maiúsculas), carece de investir-se da atitude do pesquisador $\mathrm{e}$, para tanto, perseguir estratégi as adequadas. Sobretudo, deve fazer parte da sua condição profissional sem mais, para desfazer o fardo do reles "ensinador". Não adianta muito, nessa direção, manter os ritos atuais dos centros de treinamento, geralmente voltados para ofertas operacionais e complementares, tendo em vista carências do sistema ou dos agentes, sem atentar para a "recriação" histórica do papel do professor. Na prática, se formos coerentes com qualquer proposta educativo-emanci patória, é preciso reconhecer que a dignidade do professor só pode ser elaboração própria, conquista própria. Não faz sentido esperar pacotes emancipatórios, porque seriam presentes de grego e destruição prévia da chance libertadora (Demo, 1996, p. 85).

Em outro texto, Pedro Demo descrevee comenta - um exemplo do que se tem feito com o objetivo de restaurar a auto-estima do professor:

Um episódio recentemente decantado na imprensa é ilustrativo. O governo do Paraná instituiu al go semelhante a uma universidade do professor, em Faxinal do Céu, aonde são levados os professores estaduais para um spa pedagógico. Lá permaneceram por vol ta de uma semana em êxtase maiêutico - não é certamente a maiêutica de Sócrates, que, ligada à idéia de parto, também dói - com o objeto de restaurar a auto-estima, o amor próprio e, sobretudo, a fantasia de que educar é diversão. Ouve-se que os professores saem de lá ressuscitados, acreditando, mais do que nunca, que na escola estariam redimindo o país ea si mesmos. Na prática, em vez de maiêutica, é o vel ho "pão e circo" servindo à "qual idade total ", com o resultado já conhecido: al cança-se a adesão do grupo, por vezes fascinada, encobrindo os salários miseráveis e sobretudo o despreparo para a função moderna de aprendizagem. Quando deixam a "farra", "caem na real", ou "no Real", e percebem quea vida continua andando para trás.

Não cabe defender o oposto, como se sofrer à-toa fosse mais pedagógico. De um pouco de "pão e circo" todo precisamos, porque sem um "mínimo" de "al ienação", não dá! Se fossemos viver todo dia apenas ol hando para seu lado nu e cru, acabaríamos desanimados. Que o professor recupereo gosto de educar, éal go extraordinariamenterel evantee digno, mas não a preço da fal ta de consciência crítica, que, no fundo, é marca indelével do educador. Nenhum problema é atacado em profundidade, em particular a dificuldade extrema que os al unos têm deaprender. Acaba acontecendo o mesmo que nos tradicionais "centros de treinamento": os docentes acumulam diplomas, ao passo que os al unos aprendem cada vez menos. Há alguma mentira nessa história... (Demo, 1997, p. 29-30).

No Brasil, outro programa quedemonstra a preocupação com a base do "exército", por parte da própria Fundação de Amparo à Pesquisa do Estado de São Paul o (Fapesp), foi criado e está em desenvolvimento. 
Os chamados Centros de Pesquisa, Inovação eDifusão, com recursos para desenvolver pesqui sas multidisci plinares na fronteira do conhecimento, devem contribuir para o desenvolvimento de novas tecnologias e para a criação de novas empresas, propondo uma visão integrada da atividade de pesquisa com a transferência de conhecimento para os setores públicos e privados, bem como para a educação. Como diferencial, além dos programas clássicos de graduação e pós-graduação, os centros terão ainda a responsabilidade de desenvolver atividades na área da educação básica, como cursos e treinamentos para al unos e professores de ensino médio, podendo ser expandido para o ensino fundamental.

A Fapesp tem dois outros programas de apoio ao ensino fundamental e médio, quese iniciaram nos últimos anos - Políticas Públicas e Ensino Público - , justamente diante da preocupação com o futuro da nossa ciência e tecnologia. A base do "exército" precisa ser muito boa para queos "oficiais" possam ser ai nda mel hores.

Para outros autores, como Kleiman e Moraes, ai nda temos outras preocupações equestões que precisam ser consideradas.

Assim é que, segundo essas autoras, para sefazer frente a uma sociedade injusta e desigual, é preciso formar indivíduos plenamente letrados, que possam seguir aprendendo pel o resto de suas vidas. Alunos e professores precisam se reconhecer no produto deseu trabal ho. Na escola pública brasilei ra de ensino básico, de onde procede a mai oria dos licenciados, o trabaIho do professor éalienante, porqueeleestá sobrecarregado com burocracia, com o número de horas de aula que tem de ministrar eque não Ihe deixa margem para planejar, trocar idéias com seus colegas ou mesmo estudar. Ele não se reconhece no objeto do seu trabal ho, porqueel evem sendo cada vez mais desprestigiado e mal remunerado. Além disso, diante do desemprego, da injusta distribuição de renda, da falta de perspectiva de um futuro mel hor para os al unos, o professor senteque o conteúdo transmitido pela escola pouco vai adiantar para mel horar a vida dos jovens (Kleiman; Moraes, 1999, p. 34).

Novamente, é José do Prado Martins que, ao ler e analisar este texto, entende que ele merece, também, uma dimensão histórica, ressaltando a historicidade do processo que resultou no problema abordado: afilosofia educacional utilitarista da
Academia Real Militar; a seqüência de Escol as Superiores seguindo a mesma fil osofia; a deturpação das funções das Facul dades de Filosofia, Ciências e Letras e dos Centros de Educação no contexto das universi dades - responsáveis pel a formação dos professores do ensino básico; e, finalmente, a mentalidade de muitos professores e dirigentes universitários, preparados, em sua maioria, sem a devida formação pedagógica, numa linearidade que os tornam alienados do real pedagógico e da real idadesocial .

Portanto, é certo que apenas "investir" maciçamente em educação pode não ser o suficiente.

É preciso conscientização e vontade política para melhorar, eliminar preconceitos que cada vez estão mais enraizados como, por exemplo, o de que ser professor é apenas uma forma de ascensão social ou idéias errôneas de que o fato de se ter a mesma origem social do al uno, conhecendo-a bem, permite aproximar-se mais dele, com mais facili dade, fal ar a sua linguagem, entender suas gírias, como temos lido e ouvido.

Precisamos de bem mais do que isto, e a sociedade, como um todo, terá que se fazer presente. Em particular, formar bons professores, oferecer bons cursos de licenciatura, diurnos e noturnos, val orizar o jovem que deseja seguir a carreira, não discriminá-lo sob nenhum pretexto éobrigação das Instituições de Ensino Superior, onde podemos interferir, enquanto professores e dirigentes universitários.

A importância dos professores, desdeo ensino fundamental, no desenvolvimento dos indivíduos e das sociedades é determi nantena formação de atitudes - positivas ou negativas - peranteo estudo. Cabe a el es despertar a curiosidade, desenvolver a autonomia, estimular o rigor intelectual ecriar as condições necessárias para o sucesso da educação formal eda educação permanente, val orizando o esforço dos que desejam fazer cursos deextensão ou depós-graduação, tanto lato sensu como stricto sensu.

Para melhorar a quali dade da educação oferecida, é preciso, antes detudo, mel horar a sel eção (processo de contratação), a formação, o estatuto social e as condições de trabal ho dos professores, pois estes só poderão responder ao que del es se espera, se possuírem os conhecimentos e as competências, as qualidades pessoais, as possibilidades profissionais e a motivação requeridas, conformeThompson (1995). 
Parece cada vez mais claro quea educação brasileira, para encontrar seu rumo, precisa dessa premi ssa inicial incontestável: resgatar o professor. Sem isso, nada frutifica. Nem de longe os outros componentes da escola têm a mesma força, segundo a opinião, sempre criteriosa e experiente de Pedro Demo em A nova LDB: ranços e avanços.

Para a Comissão Internacional de Especial istas, coordenada por Jacques Del ors (1999, p. 11-32) eque el aborou o Relatório para a Unesco sobre Educação para o Século XXI, a sociedade precisa ser ouvida. Dentro dos parâmetros regionais, que pode a sociedade esperar dos professores? Em termos realistas, que exigências Ihes podem ser feitas? A quecontrapartidas podem eles aspirar - condições de trabal ho, direitos, estatuto na sociedade? Quem podevir a ser bom professor, como descobrir uma pessoa dessas, formá-la e fazer preservar a sua motivação, assim como a qual idade do seu ensino?

Ensinar é uma arte, éuma ciência, eo trabal ho do professor não consistesimplesmenteem transmitir informações ou conhecimentos, mas em apresentá-los sob a forma de problemas a resolver, situando-os num contexto e col ocando-os em perspectiva, de modo que o aluno possa estabelecer a ligação entre a sua solução e outras interrogações mais abrangentes. É evi dente que, para o sucesso desse trabal ho, os professores precisam ser bem preparados.

Assim, mel horar a qual idade ea motivação dos professores deve ser uma prioridade. Melhorar a sel eção - ou o recrutamento, seusarmos a anal ogi a de Landi; estabelecer laços mais estreitos entreas universidades e os institutos de formação de futuros professores; desenvolver programas deformação continuada, quelevem os professores afamiliarizar-se com os últimos progressos da tecnologia da informação e comunicação; dar especial atenção à sel eção e ao aperfeiçoamento de professores deformação pedagógica, paraque possam contribuir para a renovação das práticas educativas; trabaIhar as questões de gestão e controle; incentivar a partici pação de agentes exteriores à escola e, final mente, oferecer condições de trabal ho e meios de ensino.

Publicações recentes, como a de Mizukami etal. (2002), anal isaram "questões teórico-metodológicas que permeiamtanto os processos deformação inicial econtinuada de professores quanto a investigação detais processos", enriquecendo mais o debateacadêmico que se trava sobre o tema- a preocupação com a formação dos professores, em particular os do ensino básico - discutindo a concepção ea problemática atual relativaà formação dosmesmos. A obraéresultado de um projeto de pesquisa aplicada, vinculada ao Programa de Ensino Público da Fapesp, que foi desenvol vido nos períodos de 1996 a 2000, em escola da redeestadual, na cidade de São Carlos-SP.

\section{Conclusão}

Para concluir, procurando ressal tar alguns pontos trazidos no texto, apresentamos uma série de questões para refl exão e queorientaram sua elaboração, sem nos preocuparmos com a ordem em que aparecem.

O perfil do professor-licenciado está mudando? A demanda das classes mais populares à profissão poderia estar associada à bai xa qual idade do ensino básico atribuída atual menteaos professores?

Ser professor-licenciado despertainteresse nos al unos mais "preparados", aqueles quetiveram oportuni dade deestudar em escolas particulares, com mais recursos e provenientes defamílias em que os pais têm grau deescol aridade mais el evado?

As instituições públicas de ensino superior estão preocupadas com a formação de professores para atuar no ensi no básico?

O professor, que está atuando no ensino básico, sabe pesquisar? Ele é capaz de refletir e produzir conhecimento?

O nível de qualificação do professorlicenciado, que está atuando no ensino básico, ébom?

Um sistema de educação básica (incluindo ensino médio) que deixe a desejar não irá comprometer, ainda que no futuro, a qualidade de nossa pós-graduação?

O Brasil corre o risco de se tornar um excluído tecnológico?

Os que "fazem" pesquisa no Brasil precisam (ou não) ser al ertados de que o ensino básico-queéa base do exército de Landi - está se degradando e que precisa ser discutido também sob outros pontos de vista?

A sociedade- por exemplo - tem participado das discussões sobrea quali iade do ensino básico? Seus representantestêm sido ouvidos pelos acadêmicos? A reflexão trazi da pel os não-acadêmi cos podeajudar, mesmo que el es deixem de anal isar aspectos considerados importantes da real idade educacional? 
Os projetos de educação continuada têm sido eficientes?

Idéias "discutíveis" - como "recrutamento" de docentes ou de que a baixa qualidade hoje atribuída aos professores estaria associada à demanda das classes mais populares pela profissão de docente - devem ser afastadas do debate ou trazidas para reflexão?

Ainda temos, além destas, muitas outras questões fervil hando em nossa cabeça. Muitas indagações ainda sem respostas. Estamos assistindo à entrada em cena de figuras como a da parceria entre universidades e escolas; os cursos de formação de professores preocupados com projetos de pesquisa que possam representar o crescimento dos alunos - futuros professores; órgãos financiadores de pesquisa investindo em projetos que objetivam mel horar o ensino básico; projetos de ciência com arte e emoção. Mas, falta muito. E é para essa discussão, para essa tomada de posição, que esperamos poder contribuir com nossas dúvidas, constatações esugestões, esperando que as mesmas possam estimular reflexões e debates sobre a mel horia do ensino.

Ao trazermos para o debate a problemática levantada na introdução do trabaIho não tínhamos a intenção de discutir as constatações apresentadas e de concluir sobreas mesmas, o quecertamente provocaria discussões profundas e que poderiam, até mesmo, inviabilizar a publicação do trabaIho, perdendo-se a oportunidade dos questionamentos colocados para reflexão pel os leitores, objetivo maior do trabal ho.

As questões col ocadas para debate poderão colaborar na reflexão sobrea preocupação manifestada no texto de que o Brasil corre o sério risco de setornar um excluído tecnológico, considerando-se que, aparentemente, as crianças - na educação básica não estariam sendo bem preparadas.

A educação básica émuito importante. O professor, que nela atua, é estratégico e devia ganhar mais, ser mais respeitado e val orizado. Sua formação deveria ser mais primorosa. O professor quesabe pensar terá al unos que saberão pensar.

Encerramos com Pedro Demo - A nova LDB: ranços eavanços- quando conclui que:

[...] a nova Lei, infelizmente, confirma: nosso novo atraso histórico não está na economia, reconhecida como já importante no mercado, mas na educação. Ou resolvemos isso, ou ficaremos para trás. O resgate completo do professor básico éa premissa primeira... (Demo, 1997, p. 95).

\section{Referências bibliográficas}

CONY, Carlos Heitor. Reflexão e produção. Folha de S. Paulo, São Paulo, 28 out. 1999. p. A2.

DELORS, Jacques (Org.). Educação: um tesouro a descobrir. 2. ed. São Paulo: Cortez; Brasília-DF: MEC, 1999. 288 p.

DEMO, Pedro. A nova LDB: ranços eavanços. Campinas-SP: Papirus, 1997. 111 p.

Conhecimento, tecnologia e formação dos professores das séries iniciais. Texto publicado em jul. 2000, UnB. Disponível em <www.anped.org.br/outrtext.htm>. Acesso em: 15 de maio de 2002.

. Pesquisa: princípio científico eeducativo. 4. ed. São Paulo: Cortez, 1996. 120 p.

FRANCO, Maria Laura P. Barbosa. Ouvindo os al unos em busca de caminhos para uma nova concepção de ciência etecnologia. Cadernos de Pesquisa, São Paulo, n. 79, p. 17-25, nov. 1991.

FURLANI, Lucia M. Teixeira. A claridade da noite: os alunos do ensino superior noturno. São Paulo: Cortez, 1998. 184 p. 
KALINKE, Marco Aurélio. Para não ser um professor do século passado. Curitiba: Expoente, 1999. Disponível em: http://www.expoente.com.br/professores/kalinke/livros/livro.htm. Acesso em: 9 mar. 2005.

HIPÓLITO, Oscar. Educação, Ciência e Tecnol ogia: investimentos estratégicos. Revista do Ensino Superior, São Paulo, v. 3, n. 33, p. 39, jun. 2001.

KLEIMAN, Angela B.; MORAES, Silvia E. Leitura e interdisciplinaridade: tecendo redes nos projetos da escola. Campinas-SP: Mercado das Letras, 1999. 191 p.

LANDI, Francisco Romeu. Um salto para o desenvolvimento. Revista Pesquisa Fapesp, São Paulo, n. 68, p. 20, set. 2001.

LÜDKE, Menga (Coord.). O professor e a pesquisa. Campinas-SP: Papirus, 2001. 112 p.

MARTINS, José do Prado. Educação cidadã e pós-modernidade. In: MARTINS, José do Prado; CASTELLANO, Elisabete Gabriela (Orgs.). Educação para a cidadania. São Carl osSP: EDUFSCar, 2003. 253 p.

MEIS, Leopol do de. Ciência com artee emoção. Revista Pesquisa Fapesp, São Paulo, n. 70, p. 88-91, nov./dez. 2001.

MIZUKAMI, Maria da Graça Nicol etti et. al. Escola e aprendizagem da docência: processos de investigação eformação. São Carlos: EDUFSCar, 2002. 203 p.

THOMPSON, A. R. The utilization and profissional development of teachers: issues and strategies. Paris: International Institut of Educational Planning, 1995. (Themanagement of teachers series).

Alberto Nicodemo Senapeschi, doutor em Ciências pela Universidade de São Paulo (USP), é professor do curso de Pedagogia do Centro Universitário Central Paul ista (Unicep) de São Carlos-SP. Foi professor da Universidade Federal de São Carlos (UFSCar). Atualmente, é diretor de pós-graduação da Unicep.

posgraduacao@unicep.com.br

\section{Abstract Bringing to debate the concern related to basic education} teachers' formation

The objective of this article is to encourage a debate about the general concern on basic education teachers training, taking into account the characteristics of technological society and the population educational needs that underlie social inclusion. In order to present and discuss the main ideas, the opinions of people from different segments of society are given. Moreover, some questions are left for further consideration so as to stimulate the debate on the issue.

Keywords: science; technology; teachers' training; basic education.

Recebido em 25 de outubro de 2003.

A provado em 16 de março de 2004. 